\title{
Possibilities for the Utilization of an Automatized, Electronic Blockchain-based, Students' Attendance Register, using a Universities' Modern Security Cameras
}

\author{
Krisztián Bálint
}

Óbuda University, Doctoral School on Safety and Security Sciences, Népszínház u. 8, H-1081 Budapest, Hungary, e-mail: balint.krisztian@phd.uni-obuda.hu

Abstract: This article introduces a solution for a security camera system, based on artificial intelligence, capable of an automatized composition of a students' attendance register, which helps in managing the in-school administrative burdens, and lessens the required paperwork, which has encumbered teachers to this day. So far, such a solution has not yet been implemented at any University. Furthermore, to keep the data storage process secure, blockchain technology will be implemented. This way, data will be stored after encryption on various nodes, increasing data security compared to the traditional, cloud-based data storage. The camera system is capable of monitoring the students' attendance of lectures. To be eligible for a so-called digital subject approval, each time a student attends a lecture, a record of facial features must include a timestamp, with the classroom number, the name of the lecturer, and the designation of the subject in question. Last, but not least, the system could be utilized in fire protection too, as, in the case of an eventual evacuation, the camera system would be able to indicate the exact position of each student within the premises, so it would provide a great asset to the rescuers and/or firemen.

Keywords: security camera; blockchain; attendance register; fire protection

\section{Introduction}

Presently, security cameras are undergoing rapid developments. These systems utilize numerous analytic solutions with large resolution, in high detail. The builtin artificial intelligence has appeared, lessening the task of rescue personnel. To further increase efficiency, the implementation of new technologies is also recommended, which were not used to these days in such a complex, composite manner. The connection of blockchain technology with the cameras' NVR (Network Video Recorder) system for data storage represents an outstanding solution. The following innovations have been brought to fruition: 
- Recently, there was a profound evolution in the use of information technology [1]. Blockchain-like data storage, will have a broad expansion in the next 3-5 years, as the presently utilized, cloud-based data storage solutions, are centralized, so users must trust providers [2]. In the case of decentralized cloud-based data storage, the clients' data are not stored on a central server, but are distributed on the blockchain's nodes [3].

- What's more, in some mid-level educational institutions, the behavior or individual pupils is monitored by cameras capable of face recognition. These cameras recognize the following patterns of behavior: writing, reading, reporting and paying close attention [4].

- These days, the Universities may compose their blockchains, aiming to close smart contracts with their students. The system is capable of monitoring students' semi-annual grades trough the in-school Neptun system, thus forming an automatized bursary payment system. If a student completes the conditions stipulated in the contract, then, he/she receives the bursary, automatically, without any need for outside intervention or supervision [5].

- The newest research has pointed out that blockchain-based data storage could be used as part of smart cities. The security cameras would save their video recordings in a blockchain. The cameras monitoring public spaces could save their data as to become irrefutable evidence in courts. This method could come to fruition through a blockchain of unalterable main ledger. The main ledger would prove that the video recordings have not been compromised, respectively, that these fully depict the true happenings in cases given [6].

- Research is moving toward issuing University Certificates, not only in a paper-based form, but also as an electronic document, issued through a blockchain. Data stored in a blockchain provides a high degree of security. With the implementation of such a method, the number of misuses could be minimized, as there were several cases of the applicants producing fake certificates to the employers [7].

- With the majority of blockchains, the records are posteriorly, not erasable, thus, Universities may constitute their own records for their students. These records would contain information about the classes visited and any payments for the tuition fees. If inaccurate data were saved in a given record, then, a new record needs to be made. By the implementation of this method, both the old and the new record would remain visible, with the divergence, that the corrected record would become relevant. By the applying of this approach, the amendments would become easily traceable and retraceable [8]. 
The automatized, electronic, blockchain-based, students' attendance register composed by the system, connected with the security cameras, is considered an outstanding solution in the educational institutions. The university which would be first to implement this feature would vouch for a modern, innovative solution.

It may be stated that the off-chain based blockchain was already composed in practice, as well as the UDSC - Universities Data Storage Chain. The blockchain technology has been linked with a security camera featuring analytical abilities and facial recognition in practice. The gained results are discussed in the paper.

This work is structured as follows: After the introduction of modern-day security camera systems, the present article discusses the blockchain-based data storage, the UDSC, the in-school off-chain software architecture, as well as the possibilities of the utilization of automatized, electronic, blockchain-based attendance registers in the educational system.

\section{Constituting Elements of a System for Composing an Automatized, Electronic, Attendance Register}

A system composing of an automatized attendance register of students, consists of numerous components, such as:

- Security cameras

- An NVR-unit

- A blockchain

- The Neptun in-school system (Student record system)

\subsection{Modern Security Camera Systems}

The administration before and during lectures is a necessary, albeit an encumbering task. It includes the register of attendance considering students and lectures. This task can be automatized by security cameras. During the practical realization of this system, security cameras were implemented featuring the following functions:

- Facial detection

- Facial recognition

- Headcount

- Black and white list

- Deep learning 
The mentioned camera functions are essential, as without these, the students' automatic recognition is not accomplishable at the universities. Moreover, it is necessary to install an NVR-unit which manages the cameras, and it stores all the recording data on its hard disk. It is expedient that the NVR would feature the following capabilities:

- Operation system. This way, the possibility is provided for the NVR's configuration, regarding all the relevant details. It is recommended to choose an NVR containing a Linux operation system for the stability of performance.

- Artificial intelligence, through which the cameras' capabilities can be fully utilized.

- Functions, such as, trigger events, like PTZ (Pan-Tilt-Zoom), video push, snapshot, or the possibility of sending automatic emails.

\subsection{Blockchain-based Data Storage}

In order to obtain secure data storage, and, if needed, a long term data saving solution, it is recommended to keep data in blockchains. The decentralization of data provides greater security and data protection. This is partly since it is harder to corrupt it in comparison with the traditional storage methods. The files are distributed between the nodes in parts, on hardware located anywhere in the world, and even the nodes involved cannot view the content of the whole file altogether [9].

As a part of the system for composing an automatized attendance register of students, a unique and proprietary, university-based blockchain was created, which is titled UDSC (Universities Data Storage Chain).

This blockchain saves the video recordings of students, and their photos (Photo IDs) utilized for personal recognition.

The solution's advantages:

- Posterior changes to the existing blockchain are almost impossible, except with the agreement of the majority of users operating the network. For an individual to be able to manipulate the blockchain, that person would have to possess at least $51 \%$ of the network (in reality, the chances for this are very slim).

- Some cloud-based providers may even amend the personal data or may delete them, or in extreme cases, may exclude a user. In the case of a blockchain, these cases cannot happen, thanks to the data savings distributed between the nodes. 


\subsection{The Connection of the NVR-Unit with the Security Cameras and the Blockchain}

To achieve the infallible operation of the in-school blockchain in practice, attention is needed to its numerous elements, by adequate configuration. As a first step, the security cameras need to be connected to the NVR-unit, as this unit is required to the cameras' operation. Next, the pitfalls are listed, which were experienced in the time period during testing stages. These were:

- The number of allocated channels from the NVR. During the testing period, a system with 4 ports was required, as there were 3 cameras installed, each with different capabilities. The institutions of education are recommended to consider a 24 port capable NVR-unit, as the number of ports determines the number of cameras in question.

- Attention must be directed to the types of compressing possibilities. The implementation of codec designated as H.264 may achieve a suitable rate of data compression, while the most effective solution is the codec H.265. Thus, valuable data storage space may be saved.

- The bandwidth and future speed of the Internet should be also considered well in advance. During the testing period, the first choice was an NVRunit which supported a slower Internet-bandwidth as the one present in the given institution of education. The supported bandwidth of the NVR was $80 \mathrm{Mbps}$, while the faculty's Internet speed was $150 \mathrm{Mbps}$. Thus, the whole bandwidth available cannot be utilized entirely. After the change of the NVR-unit, the data communication became faster, $150 \mathrm{Mbps}$ of speed was achieved through Wifi connection. As a remark, it can be added that the NVR may support different LAN or Wifi speeds.

- The maximal HDD capacity determines at each port the capacity of the hard drive, which may be connected to that port. In practice, the hard disks of 1TB capacity were chosen. It was more than enough for 3 cameras. In case of 24 cameras, implicitly, a greater capacity would be needed. If a long term application is needed, the capacity of 4TB seems to be an optimal choice.

Moreover, on the interface of the NVR, as a secondary saving place of the data recorded, the blockchain should be designated, by inserting its accurate IP address. The following school-related data is saved within the database of the blockchain:

- Photo IDs of students

- Video footage from students (it's recommended to keep these footages for just a short period, if no incidents happened, as these recordings take up a significant amount of space in the database) 
- The timetable of every student for each semester

- The timetable of every lecturer for each semester

- The timetable for every classroom including time and subject

\subsection{The Neptun In-School System}

The Neptun in-school system may be connected with the system for composing the automatized, electronic attendance register, including the blockchain. The Neptun system is a software used by institutions of higher education in Hungary. It is a unified scholastic system (ETR), readily accessible through the Internet by the students and the employees in higher education alike. The Neptun system consists of two modules: the one for students and the one for teachers. With the help of the students' module the students are able to:

- Select a subject

- Enlist for an exam

- View descriptions of subjects they have selected

- Pay exam fees through an escrow account

The module for the teachers allows for:

- The provision of information for students through email

- The designation of grades for the subjects taken by individual students

- The reservation of rooms for exams

- The courses of action in connection with the term papers

\section{The Constitution of UDSC (Universities Data Storage Chain)}

In order to achieve secure data storage, as a part of realization in practice, a blockchain was created. The NVR has saved its recordings to this UDSCblockchain. It is recommended to direct attention to the following aspects when creating such a type of blockchain:

- The accessibility address of the database. This consists the accessibility to both the sending and the receiving party

- $\quad$ The address of the camera system 
- The designation of a correct server address. In order to increase the security and to keep the system at continuous readiness, it is recommended to have two servers allocated to the blockchain.

As long as the blockchain has been created correctly, the genesis block will appear. Table 1 introduces the steps of the blockchains' creation:

Table 1

The database based blockchain creating process [5]

University chain-util generate UDSC

the default settings would be used:

/default universitychain/UDSC/chainsettings.dat

chainsettings.dat include:

Database addresses [receiver (cloud storage) IP address, sender (university) IP address], Camera system addresses [receiver (Neptun system) IP address, sender (NVR) IP address], Terms of GDPR database.

Next, the UDSC blockchain would be initialized, and the genesis block would be created universitychain UDSC

The server will be started in those few seconds after the genesis block has been found, then the node address needs to be connected:

\section{UDSC@192.168.0.1:8008}

After these steps, the connection can be attempted from a second server:

universitychain UDSC@192.168.0.1:8008

After the message confirming the chain has been initialized, the permission is not given for connection to the database. The address would be copied and pasted: 192.168.0.2

finally, permission for connection would be granted:

universitychain UDSC grant 192.168.0.2 connect 


\section{Possibilities of the Utilization of an Automatized, Electronic Blockchain-based, Students' Attendance Register in the Educational System}

These days, intelligent security cameras possess numerous abilities that have been unthinkable just a few years ago. These would be the following abilities:

- Detection of sabotage

- Rambling

- Detection of over-crowding

- Identification of license plates

The mentioned video analytic solutions, however, can be utilized only less efficiently in the education, contrary to the possibility of the composition of an electronic attendance register.

The in-school administrational burdens have kept growing lately, and the tasks to be completed have not been significantly diminished either. Furthermore, the digitalized data should be specially attended, due to its sensitivity, or rather, to avoid its corruption. Complying with the GDPR law is not an easy task either, putting a considerable burden on the IT experts, and the school management. The storing of the recorded footage by a blockchain would be a secure solution foreshadowing progress.

The USDC system's structure and its operation is happening in the following manner:

1) As a first step, students' names (first and last names in correct order) need to be uploaded into the camera's database. Next, the categorization is recommended to separate the students' names by study groups, branches, on behalf of better transparency. This is needed because it may happen that the camera's artificial intelligence cannot recognize the student, thus it is unable to allocate a name to the face given. In such situations, the manpower should step in, and a member of the security personnel should identify the student in question. Seeking out a student's name from a manageable database is a much easier and more efficient solution.

2) As a second step, profile images in high resolution (at least in HD) are allocated to the names. Based on these two important data (by possessing the name and the Photo ID of a student), the system is capable of the student's identification. This is not only necessary because of the attendance register, but also for filtering out the trespassers more easily, thus raising the level of security applied. This solution operates based on a black and white list, which ability is already included in modern cameras. 
3) Following these steps, the number and designation of the classrooms must be uploaded into the camera's database. It is recommended to register all the classrooms within the system. By designations, the specificities of the mentioned classrooms are meant, like computer science, chemistry or biology classrooms.

4) The timetable represents the next step. In the long term, this is the most time-consuming task in this system, as the timetable is changed in each semester, and it is necessary to record it twice a year. To increase efficiency, importing from the Neptun software is recommended.

5) After the uploading of the complete database, the identification of the individuals follows, within this, the face detection, which is an essential part of this technology. Face detection is a very complex task, as in the case of an educational institution, the camera needs to sense multiple faces in a single time frame.

6) After the camera has detected a face, it needs to be identified, by matching it with a database entry, which gets assigned with a name by the system.

7) In possession of adequate data, the system would compose an attendance register. Its most crucial condition is the successful identification, and the gaining and mutual connection of preprogrammed data.

8) As the last step, data is sent in predefined periods. This may happen:

- Daily

- Weekly

- Monthly

- Semi-annually

It is important to determine who is receiving these notifications. It is recommended to designate a lecturer, a student, and the Neptun system respectively. In that case, the lecturer and the student both receive the report about the attendance. This way, even the eventual misunderstandings may be corrected, which would stem from an incorrect identification, and the problem may be solved in a short time.

\section{Experiences Gained During the Realization in Practice}

There were numerous hardships and problems which have surfaced during the realization of the system for composing an attendance register. One of these is the huge data quantity generated by the cameras, which was, at first, saved on the 
NVR hard drive. After this, the system has forwarded the data to the blockchain. The subject of the examination was the control of the cameras' face recognition capability, respectively the examination of the efficiency.

\subsection{The Data Quantity Generated by the Cameras}

The cameras' deployment was completed in 3 phases. This was done in the following manner:

- First, the cameras with minimum HD resolution, were installed and tested

- Then, the cameras with 2 MP resolution were implemented

- $\quad$ Last, but not least, modern $10 \mathrm{MP}$ capable security cameras were tested

During the testing phase, the most efficient compressing process was implemented, namely, the standard H.265. The obtained results lead to the following conclusions:

- The security cameras with HD resolution are capable of producing recordings of sufficient quality. The higher resolution has produced a significantly larger data quantity, which represents a greater problem than it would be an advantage during the daily use. The HD resolution has proven to be sufficient, because these cameras were deployed indoors, with the premises lacking great distances. The cameras were placed in front of the classrooms' entrances, so it was possible to produce recordings of sufficient quality of students passing in front of the cameras.

- The cameras featuring $2 \mathrm{MP}$ of resolution have produced a much larger data quantity, but their capabilities of face recognition have proven higher.

- The security cameras featuring $10 \mathrm{MP}$ of resolution have produced recordings in astounding detail. Hypothetically, the broad implementation of these devices is an image from a farther future, since their high price may hinder the propagation. The greatest problem was, however, the data quantity, generated on a daily basis. Currently, storing of huge data quantity represents a problem for the in-school systems.

- Furthermore, the increased data traffic must be taken into account, as this has significantly burdened the Internet managing system of the educational institution in question. This was mainly typical for the cameras featuring $10 \mathrm{MP}$ resolution. The data transfer to the blockchain is recommended to take place in the evening hours, when there is no other data traffic in the educational institution. The second table shows the data quantities generated by the security cameras: 
Table 2

The data quantity generated by the security cameras in practice

\begin{tabular}{|c|c|c|c|c|c|c|}
\hline Resolution & $\begin{array}{l}\text { Process of } \\
\text { compression }\end{array}$ & $\begin{array}{l}\text { Number } \\
\text { of } \\
\text { cameras }\end{array}$ & $\begin{array}{l}\text { Number } \\
\text { of days }\end{array}$ & $\begin{array}{l}\text { Number of } \\
\text { daily } \\
\text { hours in } \\
\text { use }\end{array}$ & $\begin{array}{l}\text { Bandwidth } \\
\text { of the } \\
\text { network }\end{array}$ & $\begin{array}{l}\text { Data } \\
\text { quantity }\end{array}$ \\
\hline $\begin{array}{c}1.3 \mathrm{MP} \\
\text { (HD) }\end{array}$ & H.265 & 3 & 5 & 12 & $150 \mathrm{Mbit} / \mathrm{s}$ & $470 \mathrm{~GB}$ \\
\hline $2 \mathrm{MP}$ (HD) & H.265 & 3 & 5 & 12 & $150 \mathrm{Mbit} / \mathrm{s}$ & $710 \mathrm{~GB}$ \\
\hline $10 \mathrm{MP}$ & $\mathrm{H} .265$ & 3 & 5 & 12 & $150 \mathrm{Mbit} / \mathrm{s}$ & $3.2 \mathrm{~TB}$ \\
\hline
\end{tabular}

\subsection{The Cameras' Efficiency of Identification}

Presently, facial recognition represents one of the most significant challenges in these fields of technology. According to past experiences, the comparison of camera images with database entries is not a simple task. If the system handles a substantial database, these interfering effects could highly debase the success rate of recognition [10].

The cameras' testing in practice was performed in the following manner:

- The entire testing period lasted 6 weeks

- There were 2 weeks assigned for each of the 3 camera types

It is important to note, that these cameras were all featuring built-in artificial intelligence. Since the testing was performed at the university, there were encumbering circumstances uncovered during the trials, which have negatively influenced the success of the identification. The following factors were encountered:

- Facial expression:

- The identification may be hindered even by a smile, as it changes the lineaments of a face.

- Various coverings:

- In front of the classroom entrances, the students may cover each other's faces, even by chance.

- Image quality:

- Insufficient lighting conditions, improper shading (regardless of which, the sunshine is still obstructing the lens),

- Choice of the appropriate resolution, image frequency, and color depth. 
- Presence or absence of facial traits:

- Hair, beard, mustache, glasses,

- A multitude of colors, shapes, and sizes [11].

There were 57 students participating in the present research, all studying the subject Computer Science 1. In practice, this meant 3 groups. An important aspect was, that in case of all 3 cameras, the participants were the same. This way, the possibility was given for determining the cameras' capability and precision of identification. The six-week period has lasted from mid-January to the end of February 2020. It was a relevant aspect that the cameras be implemented in quick succession. During the winter season testing, the clothing habits and hairdo of the students was similar in the time period examined. If some of the cameras were deployed in winter and some tested in the summer, the precision of the identification would have shown greater discrepancies, which would have had a negative influence on the accuracy of the measurement. Therefore, the primary aim was the provision of nearly equal conditions. The results of the identification are shown in the third table:

Table 3

The cameras' efficiency of identification

\begin{tabular}{|c|c|c|}
\hline Groups of resolution & $\begin{array}{l}\text { Accurate identification of } \\
\text { students during week 1 }\end{array}$ & $\begin{array}{l}\text { Accurate identification of } \\
\text { students during week 2 }\end{array}$ \\
\hline 1.3 MP (HD) camera & 43 & 51 \\
\hline 2 MP (HD) camera & 46 & 52 \\
\hline 10 MP camera & 51 & 55 \\
\hline
\end{tabular}

As it can be seen, the cameras were operating more efficiently during week 2, as the week before. This was due to the built-in artificial intelligence. The cameras were learning continuously, thus, the efficiency of the identification was improved significantly at the end of the testing period. Based on the results obtained, it may be stated:

- While the camera featuring 1.3 MP resolution has identified the students with $75 \%$ of efficiency during the first week, it succeeded to identify them correctly with $89 \%$ efficiency during the second week.

- The camera featuring the 2 MP resolution could reach efficiency of $80 \%$, during the next week it was operating with $91 \%$ efficiency.

- Last, the camera featuring $10 \mathrm{MP}$ of resolution has reached $89 \%$ of efficiency during week 1, and 96\% during week 2 .

Presumably, the higher pixel density has great influence on the efficiency of the identification, but the real answer is a more complex one. With the increasing of the number of pixels, the strength of the cameras' processors has proportionately increased. Henceforth, the discrepancy between the built-in artificial intelligence 
software may be examined, but the manufacturer did not share this information on the packaging, nor it is featured on their home websites.

Moreover, the connection between the NVR and the blockchain has been established successfully, so the safe storage of the data was secured. The nodes have stored the data (video recordings and photographs alike) but this has taken longer than the anticipated time was. The traditional, cloud-based systems are thus faster. The presumable answer is, that the blockchains will become truly efficient, if these run on a high number of machines. Only two machines were utilized during the present research. The detailed examination of this problem would definitely require further research, in multiple directions.

\section{Modern Solutions for Fire Protection}

In fire protection, the human factors' influences are majorly appearing during evacuations. Individuals are not properly prepared, they may be confused, unable to measure correctly, and often make faulty decisions, which may cost their lives [12].

Although the universities may have practice drills of correct steps of evacuation, possibly saving students' lives. This does not need additional financial support or any investments, as it is merely a question of organization. Hence, in case of a fire alarm, the students will know the proper behavior and may evacuate the educational institution in an orderly manner [13].

Despite this, it is presumable that there would be some students who would be puzzled or forgot to behave correctly in case of a fire. The camera system introduced in this paper would help even in these situations, as the system is capable of composing an attendance register, so it has to know by name, who is where and in which classroom in a given moment. This would facilitate the firemen's efforts, as they would receive important information on potential wounded and stuck individuals left behind.

\section{The General Data Protection Regulation and Laws Governing Electronic Surveillance Systems}

The in-school security cameras are necessary, but one must not forget that if these record information containing names, then it may violate the given individuals' rights. The images, recorded for security reasons may always be misused for illegal purposes. In these circumstances, it is self-explanatory that the use of such systems must be regulated by law [14]. 
The EU has reached an agreement on the $6^{\text {th }}$ of April, 2016 about the great reform of its legal framework regulating the data protection, by implementing the reform package containing the General Data Protection Regulation, which has superseded the twenty-year-old Directive 95/46/EU and the Police Directive. As the GDPR's provisions have been mandatory from $25^{\text {th }}$ May 2018, to comply with her set of regulations about data protection with the GDPR, Hungary has, on the $25^{\text {th }}$ of August 2018 passed the first amendment of her Act of the Informational Selfdetermination and Liberty of Information, first implemented as Act no. CXII of 2011 while, on the $26^{\text {th }}$ of April 2019 the GDPR - 'Salad' Act [15] has been proclaimed, which will be discussed in detail on the following pages.

\subsection{Data Usage of Electronic Surveillance Systems - GDPR 'Salad' Act}

The retention of security footage has, up to these days, been regulated to last for a set time. The camera footage has had to be erased after 3 workdays. The majority of security systems have deleted the footage automatically within the set time, but this has caused complications too, as it was impossible for the system to interpret the notion of workdays. Furthermore, causes have surfaced, at the data managers' side, which required a longer time for data retention. These restrictions were lifted from the $26^{\text {th }}$ of April. According to the new regulations, the data managers behave correctly even if they prolong the time of safekeeping if need be.

Before the amendment, a person entering an area under camera surveillance has had to accept the surveillance's data handling by seeing the notices put forth, and proceeding to the area. If the person did not agree, the data management was not equitable. The norms of the new EU regulation unambiguously exclude the consent given by behavior. After the amendment, the data managers had to face a new situation: they act equitably if they declare the legal base for their personal and goods protection surveillance as a legitimate interest. Therefore, in that case, no consent is needed, but an interest measuring test is required, which confirms the legal interest for data management considering every camera, yielding the possibility for data management this way [16].

The strict regulations concerning recorded footage were deleted, thus, nobody would need to prove his/her right to gain insight into the recorded footage. In the future, the camera footage will not only be used in case of jurisdiction or governmental processes.

As a new regulative of the mentioned law, the electronic records are acknowledged as official records [17].

\section{Conclusions}

As a summary, it can be stated, that the system constituting an attendance register based on security cameras consists of many components. The constitution of a 
proprietary, university-based blockchain may be suggested, which would facilitate the storing of the data on its nodes. The connection of the NVR with the UDSC would provide a possibility to secure data storage, furthermore, it would become possible to send the data through the Internet to the university based Neptun system. Thus, a student is recorded each time upon visiting a class, in the given semester. It is expedient to use a security camera featuring a Deep Learning function, as facial detection, facial identification and head counting are functions utilized during the identification.

It is noteworthy, that the system could be successfully utilized in fire protection too, regarding the rescue of human lives, as the camera system keeps track of the location of every student within the premises. Thus, it is possible to find lost students.

In addition, the amended GDPR law of data protection enables data storage for longer than 3 days, which is necessary in these cases, as it is recommended to keep the students' data for one whole semester, e.g. 6 months.

Last, student awareness has also been explored, considering a camera system capable of facial recognition and composing of an attendance registry/study behavior. 59\% of the students find that a solution capable of generating an attendance registry is important and the majority stated they would not be offended by the facial recognition technology.

\section{References}

[1] Dóra Mattyasovszky-Philipp, Bálint Molnár: An Architectural Approach to Cognitive Information Systems, Acta Polytechnica Hungarica, Volume 17, Issue Number 2, 2020

[2] Huffpost: 5 Blockchain Applications That Are Shaping Your Future, https://bit.ly/39YIWDU (Download time: 2020-02-27), 2017

[3] Cathy Sturges: Cointelegraph - How Can Blockchain Improve Date Storage, https://bit.ly/2GXBrzC (Download time: 2020-02-27), 2020

[4] Dezső András: The digital dictatorship has been built before our eyes, (A szemünk előtt épült ki a digitális diktatúra) https://bit.ly/392zwpW, (Download time: 2020-02-27) 2018

[5] Bálint Krisztián: Connecting Bitcoin Blockchain with Digital Learning Chain Structure in Education, Acta Polytechnica Hungarica, Volume 16, Issue Number 1, 2019

[6] Prince Waqas Khan, Yung-Cheol Byun,Namje Park: A Data Verification System for CCTV Surveillance Cameras Using Blockchain Technology in Smart Cities, MDPI Journal Electronics, 2020

[7] Getting Smart: How Blockchain Could Impact Education in 2020 and Beyond, 2020. https://bit.ly/3jo7utd (Download time: 2020-10-24), 2020 
[8] Maureen Hance: What is Blockchain and How Can it be Used in Education, https://bit.ly/34pffea (Download time: 2020-10-24) 2020

[9] Patrick Nelson: How Data Storage Will Shift to Blockchain, https://bit.ly/31seGNG (Download time: 2020-02-27) 2019

[10] Öszi Arnold: E-Commerce Requirements for Biometrics Business Development in the $21^{\text {st }}$ Century, (Az e-kereskedelem elvárásai a biometriával szemben Vállalkozásfejlesztés a XXI. században), Business development in the XXI. century, Budapest 2014

[11] Mastusinka Roland: Basics of Face Recognition and Face Detection, (Az arcferlismerés és arc detektálás alapjai), National University of Public Service, https://bit.ly/2vfgsFO (Download time: 2020-02-27) 2014

[12] Schüller Attila: Examination of the human factor and technical realizations during fire alarms, (Az emberi tényező és a technikai megvalósítások vizsgálata tüzriadók során), Hadmérnök, 2, Number, 37-46, 2012

[13] Bálint Krisztián: Experiences of Secondary School Teachers from Subotica, Vojvodina Regarding Electronic and Mechanical Protection at School, FMTÜ XXIII, 2018

[14] André Vitalis: Camera surveillance, security and liberties, (Kamerás megfigyelés, biztonság és szabadságjogok), Information Society 2.1: 56-57, 2002

[15] Detektor Plus The Security of Page: GDPR Major Changes (A GDPR kapcsolatos fontosabb változások), Volume 26, Number 6, https://bit.ly/396g8bG (Download time: 2020-02-27) 2019

[16] Réti, Várszagi és Társai Ügyvédi Iroda: GDPR Salad Leaf 1. - Rules for Camera Surveillance and Electronic Access Control Relaxed GDPR Salátalevél 1, (Lazultak a kamerás megfigyelés és az elektronikus beléptetés szabályai), https://bit.ly/31x8F2s, (Download time: 2020-02-27), 2019

[17] Mihola Réka: The rules for camera surveillance have been relaxed, (Lazultak a kamerás megfigyelés szabályai), https://bit.ly/3bAzyXF, (Download time: 2020-02-27), 2019 